\title{
Efektivitas dental health education dengan media animasi kartun terhadap perubahan perilaku kesehatan gigi dan mulut Siswa SD Advent 02 Sario Manado
}

\author{
${ }^{1}$ Meartriecs Tandilangi \\ ${ }^{2}$ Christy Mintjelungan \\ ${ }^{2}$ Vonny N.S Wowor \\ ${ }^{1}$ Kandidat Skripsi Program Studi Pendidikan Dokter Gigi Fakultas Kedokteran \\ ${ }^{2}$ Program Studi Pendidikan Dokter Gigi Fakultas Kedokteran \\ Universitas Sam Ratulangi Manado \\ Email: tmeartriec \\ s@yahoo.com
}

\begin{abstract}
In Indonesia, dental health is still an issue dominated by caries and periodontal disease. The poor behavior of dental health maintenance plays an important role in the occurrence of these two diseases. Intervention through education can improve the behavior. Educational success in terms of behavior change is influenced by using auxiliary media. Animated cartoon is an auxiliary media that is more attractive than the other media because it combines sound and moving images in the delivery of information. This study aimed to obtain the effectiveness of dental health education using cartoon animation media to behavioral change of oral health maintenance among students of SD Advent 02 Sario. This was a quasi-experimental study with a nonequivalent control group design. Samples were students of SD 02 Advent Sario aged 10-12 years obtained by using the purposive sampling method. The samples were divided into two groups: the treatment group using cartoon animation media and the control group without auxilary media. The measurement of the behavior of dental and oral health care of children resulted in an increase in the scores of pretest to post-test 2 by 633 which was categorized as good. Statistical analysis showed that the p-values (significance) of dental health education with media animated cartoons from pretest to post-test 1 and from post-test 1 to post-test 2 both were $0.000(<0.05)$. Conclusion: Dental health education using animated cartoon media effectively improved the behavior of oral health maintenance.
\end{abstract}

Keywords: dental health education, cartoon animated, behavior

\begin{abstract}
Abstrak: Di Indonesia kesehatan gigi dan mulut masih menjadi masalah yang didominasi oleh penyakit karies dan periodontal. Perilaku pemeliharaan kesehatan gigi yang buruk berperan penting bagi terjadinya kedua penyakit tersebut. Intervensi melalui pendidikan dengan menggunakan media bantu dapat dilakukan untuk merubah perilaku. Animasi kartun merupakan media bantu yang mempunyai daya tarik lebih dibandingkan dengan media lainnya karena memadukan suara dan gambar bergerak dalam penyampaian informasi. Penelitian ini bertujuan untuk mengetahui efektivitas dental health education media animasi kartun terhadap perubahan perilaku pemeliharaan kesehatan gigi dan mulut anak SD Advent 02 Sario. Jenis penelitian ialah quasi eksperimen dengan nonequivalent control group design. Sampel penelitian yaitu siswa SD Advent 02 Sario yang berusia 10-12 tahun yang diperoleh dengan purposive sampling. Sampel dibagi menjadi dua kelompok, yakni kelompok perlakuan menggunakan media animasi kartun dan kelompok kontrol tanpa media bantu. Hasil pengukuran perilaku pemeliharaan kesehatan gigi dan mulut anak menunjukkan adanya kenaikan jumlah skor nilai pre-test ke post-test 2, dengan selisih kenaikan sebesar
\end{abstract}


633 yang termasuk pada kategori baik. Hasil uji statistik menunjukkan nilai p (signifikansi) dental health education dengan media animasi kartun dari pre-test ke post-test 1 maupun post-test 1 ke post-test 2 masing-masing sebesar $0,000(<0,05)$. Simpulan: Dental health education dengan media animasi kartun efektif merubah perilaku pemeliharaan kesehatan gigi dan mulut menjadi lebih baik.

Kata kunci: dental health education, animasi kartun, perilaku

Kesehatan tubuh termasuk kesehatan gigi dan mulut merupakan hal yang penting dari setiap individu. Demikian pula halnya dengan kesehatan gigi dan mulut karena gigi dan gusi yang rusak dan tidak dirawat akan menyebabkan rasa sakit, gangguan pengunyahan, gangguan pada estetik dan kesehatan secara keseluruhan. Jika kesehatan gigi dan mulut terganggu dapat menyebabkan berbagai penyakit di rongga mulut. Rongga mulut merupakan tempat yang rentan dan sering mengalami infeksi peradangan di dalam tubuh karena merupakan pintu masuk mikroorganisme. ${ }^{1}$

Di Indonesia kesehatan gigi dan mulut masih menjadi masalah. Masalah ini tergambar dari tingginya prevalensi penduduk yang bermasalah gigi dan mulut di Indonesia melalui hasil laporan Riset Kesehatan Dasar (Riskesdas). Berdasarkan Riskesdas tahun 2013 angka permasalahan gigi dan mulut di Indonesia mencapai $25,9 \%{ }^{2}$ Penyakit gigi dan mulut menempati peringkat ke- 6 dari 10 penyakit rawat jalan terbesar di Indonesia, ${ }^{3}$ dimana penyakit gigi dan mulut yang paling banyak diderita ialah karies dan penyakit periodontal. ${ }^{4}$ Data Riskesdas 2013, menunjukkan bahwa anak pada kelompok usia 10-14 tahun yang memiliki permasalahan kesehatan gigi dan mulut sebesar $25,2 \% .^{2}$ Salah satu faktor penyebab terjadi kedua penyakit ini ialah faktor perilaku. Perilaku yang cenderung mengabaikan kebersihan gigi dan mulut umumnya dilandasi kurangnya pengetahuan tentang kesehatan gigi dan mulut serta pemeliharaannya.

Upaya meningkatkan pengetahuan tentang pemeliharaan kesehatan gigi dan mulut dapat dilakukan antara lain melalui dental health education (Pendidikan kesehatan gigi dan mulut). Pendidikan kesehatan gigi dan mulut merupakan suatu usaha atau aktivitas yang dapat mempengaruhi individu untuk memiliki perilaku kesehatan gigi dan mulut yang baik. ${ }^{5}$ Tujuan akhir pendidikan kesehatan gigi dan mulut yakni terjadinya perubahan perilaku yang meliputi pengetahuan, sikap dan tindakan yang mengarah kepada upaya hidup sehat. ${ }^{6}$

Keberhasilan pendidikan dalam hal perubahan perilaku dipengaruhi oleh metode pendidikan yang digunakan. Metode pendidikan dengan menggunakan alat bantu pendidikan yang melibatkan indera sebanyak mungkin akan memengaruhi keberhasilan pemahaman sasaran pendidikan. Metode pendidikan yang menggunakan animasi kartun merupakan salah satu bentuk media audiovisual yang dikenal sebagai metode pendidikan kesehatan gigi yang menarik. Media audiovisual dapat menyampaikan pengertian atau informasi dengan cara lebih nyata melalui gambar bergerak dan suara. Animasi kartun mempunyai daya tarik lebih dibandingkan dengan media lain karena memiliki simbol-simbol tertentu yang menyebabkan kelucuan. Media ini memanfaatkan indera pendengaran dan penglihatan. Semakin banyak indera yang digunakan untuk merekam informasi, semakin besar kemungkinan memahami maksud informasi yang disampaikan. ${ }^{7}$

Masa perkembangan anak merupakan awal dari pembentukan perilaku, oleh sebab itu pendidikan kesehatan gigi dan mulut pada anak sangat menentukan pembentukan perilaku kesehatan gigi anak. $^{8}$ Pada kelompok usia 10-12 tahun minat belajar anak tinggi, didukung oleh ingatan yang kuat serta kemampuan dalam memahami materi yang diberikan. ${ }^{9}$

Penelitian ini bertujuan untuk 
mengetahui efektivitas dental health education dengan media animasi kartun terhadap perubahan perilaku pemeliharaan kesehatan gigi dan mulut pada anak. Peneliti memilih SD Advent 02 Sario sebagai lokasi penelitian dikarenakan hasil survei awal menunjukkan penyakit karies gigi masih menjadi masalah utama pada kesehatan gigi dan mulut siswa SD Advent 02 Sario. Di samping itu selama ini belum pernah ada penyuluhan kesehatan gigi dan mulut yang dilakukan di sekolah tersebut.

\section{BAHAN DAN METODE PENELITIAN}

Jenis penelitian ini ialah quasi eksperimental dengan nonequivalent control group design. Penelitian dilaksanakan di SD Advent 02 Sario pada bulan Februari-Agustus 2016. Populasi dalam penelitian ialah seluruh siswa SD Advent 02 Sario berusia 10-12 tahun yang berjumlah 105 murid. Besar sampel dihitung dengan rumus Slovin didapatkan sebesar 52 responden. Responden dibagi dalam 2 kelompok, 26 pada kelompok perlakuan dan 26 pada kelompok kontrol. Penilaian perilaku pemeliharaan kesehatan gigi dan mulut dilakukan dengan menggunakan kuesioner perilaku pemeliharaan kesehatan gigi dan mulut. Data diolah mengunakan SPSS dengan uji Wilcoxon dan disajikan berdasarkan distribusi dalam bentuk tabel.

\section{HASIL PENELITIAN}

Tabel 1. Distribusi karateristik responden berdasarkan usia

\begin{tabular}{ccc}
\hline $\begin{array}{c}\text { Usia } \\
\text { (tahun) }\end{array}$ & $\mathbf{n}$ & $\mathbf{( \% )}$ \\
\hline 10 & 30 & 57,7 \\
11 & 17 & 32,7 \\
12 & 5 & 9,6 \\
Total & 52 & 100,00 \\
\hline
\end{tabular}

Tabel 2. Distribusi karakteristik responden berdasarkan jenis kelamin

\begin{tabular}{ccc}
\hline Jenis kelamin & $\mathbf{n}$ & $\mathbf{( \% )}$ \\
\hline Laki-laki & 23 & 44,2 \\
Perempuan & 29 & 55,8 \\
Total & 52 & 100,00 \\
\hline
\end{tabular}

Tabel 3. Distribusi skor perilaku pemeliharaan kesehatan gigi dan mulut

\begin{tabular}{ccccc}
\hline \multicolumn{5}{c}{ Skor Perilaku } \\
Kelompok & Pretest & Posttest & Posttest & Selisih \\
& & 1 & 2 & \\
\hline Perlakuan & 916 & 1199 & 1549 & 633 \\
Kontrol & 903 & 988 & 1141 & 238 \\
\hline
\end{tabular}

Tabel 4. Hasil Uji Wilcoxon

\begin{tabular}{lcc}
\hline Perilaku & Mean & $\mathrm{p}$ \\
\hline Pretest & 35,23 & 0,000 \\
Posttest 1 & 46,12 & \\
Posttest 2 & 59.58 & \\
\hline
\end{tabular}

\section{BAHASAN}

Pada penelitian ini didapatkan data karakteristik berdasarkan usia dan jenis kelamin. Responden terbanyak berusia 10 tahun $(57,7 \%)$ (Tabel 1). Hal ini disebabkan karena responden merupakan siswa SD kelas 4 dan 5 dimana populasi usia 10 tahun banyak tersebar. Berdasarkan jenis kelamin, subjek berjenis kelamin perempuan (55,8\%) lebih banyak disbandingkan dengan subjek berjenis kelamin laki-laki (44,2\%) (Tabel 2).

Data Tabel 3 menunjukkan bahwa jumlah skor pre-test pada kedua kelompok rendah; hasil ini menunjukkan bahwa siswa SD Advent 02 Sario masih memiliki perilaku yang kurang baik tentang pemeliharaan kesehatan gigi dan mulut, karena sebelumnya siswa belum pernah diberikan penyuluhan tentang pemeliharaan kesehatan gigi dan mulut. Tabel 3 juga menunjukkan bahwa adanya peningkatan jumlah total skor hasil pengukuran perilaku anak dari pre-test ke post-test 1 dan dari post-test 1 ke post-test 2 pada responden kelompok perlakuan maupun kelompok kontrol. Keadaan ini menunjukkan bahwa pemberian dental health education dengan media animasi kartun dan tanpa media bantu memiliki kemampuan untuk merubah perilaku responden dalam pemeliharaan kesehatan gigi dan mulut. Hasil skor akhir menunjukkan bahwa skor perilaku kelompok perlakuan sebesar 1549 termasuk pada kategori baik. Skor akhir kelompok 
kontrol sebesar 1141 termasuk pada kategori kurang baik.

Hasil uji statistik menunjukkan data tidak terdistribusi normal, maka dilanjutkan dengan uji alternatif t-berpasangan, yaitu uji Wilcoxon. Berdasarkan hasil uji Wilcoxon (Tabel 4) didapatkan nilai signifikansi pre-test ke post-test 1, maupun dari post-test 1 ke post-test 2 dengan pemberian dental health education menggunakan media animasi kartun sebesar 0,000. Data ini menunjukkan adanya adanya peningkatan skor nilai ratarata perilaku pada kelompok perlakuan setelah pemberian dental health education dengan media animasi kartun.

Hasil penelitian ini sejalan dengan penelitian yang dilakukan oleh Sinor ${ }^{10}$ yang membandingkan promosi kesehatan gigi metode konvensional dengan animasi kartun dalam menyampaikan pendidikan kesehatan gigi di Kuala Lumpur. Simpulan yang diperoleh menunjukkan media animasi kartun efektif dan berkelanjutan dalam menyampaikan pesan-pesan kesehatan gigi. ${ }^{10}$ Hasil yang hampir serupa disimpulkan lewat penelitian yang dilakukan oleh Riyanti ${ }^{11}$ tentang upaya kesehatan gigi dan mulut melalui perubahan perilaku. Simpulan penelitian Riyanti menyatakan bahwa dental health education merupakan salah satu upaya yang dapat meningkatkan kesehatan gigi dan mulut pada anak melalui perubahan perilaku anak terhadap pemeliharaan kesehatan gigi dan mulut.

Pemanfaatan media animasi kartun dalam dental health education tidak hanya dapat menghasilkan cara belajar yang efektif dalam waktu singkat tetapi menghasilkan kesimpulan bahwa sesuatu yang diterima melalui audiovisual akan lebih lama dan lebih baik dalam ingatan karena melibatkan lebih banyak panca indera. ${ }^{10}$ Notoatmodjo ${ }^{12}$ menyatakan bahwa video merupakan alat bantu pendidikan yang bertujuan untuk menyampaikan pesan kesehatan dengan menstimulasi indra penglihatan dan pendengaran. Peningkatan pengetahuan responden dipengaruhi oleh adanya bantuan media animasi kartun berupa gambar bergerak dan suara yang memudahkan responden dalam mengingat materi yang diberikan. ${ }^{13}$ Penelitian yang dilakukan Nurhidayat $^{14}$ tentang peningkatan pengetahuan siswa tentang kesehatan gigi dan mulut dengan menggunakan media menyimpulkan bahwa untuk meningkatkan kemampuan mengingat siswa, diperlukan media sebagai alat bantu dalam menyampaikan informasi. Media animasi kartun mempunyai kemampuan besar untuk menarik perhatian, memengaruhi sikap maupun tingkah laku. ${ }^{7}$ Pada penelitian yang dilakukan terlihat bahwa penggunaan media animasi kartun juga memengaruhi perubahan sikap responden menjadi semakin baik setelah melihat tayangan animasi kartun. Azwar ${ }^{15}$ menyatakan bahwa faktor-faktor yang memengaruhi sikap ialah media penyampaian informasi sebagai tugas pokok yang berisi sugesti untuk mengarahkan opini seseorang. Bila sugesti cukup kuat maka akan memberi dasar afektif dalam menilai sesuatu hal sehingga terbentuk arah sikap yang diwujudkan melalui tindakan.

\section{SARAN}

1. Disarankan agar pemerintah dapat mendorong penggunaan media bantu animasi kartun guna meningkatkan efektivitas pendidikan kesehatan gigi dan mulut pada anak sekolah dasar.

2. Disarankan kepada masyarakat dalam hal ini anak-anak sekolah dasar yang telah menerima pendidikan kesehatan gigi lewat media animasi kartun, agar dapat mempraktekkan informasi kesehatan yang telah diterima guna terjadinya perubahan perilaku pemeliharaan kesehatan gigi dan mulut ke arah yang lebih baik.

3. Disarankan hasil penelitian dapat dipraktekkan oleh para mahasiswa dalam pembelajaran yang dilakukan di Program Studi Pendidikan Dokter Gigi Unsrat terlebih dalam bidang Ilmu Kedokteran Gigi Masyarakat dan Pencegahan. 
DAFTAR PUSTAKA

1. Indriastuti L. Pengaruh pendidikan kesehatan gigi (DHE) terhadap indeks plak penderita schizophrenia di Rumah Sakit Jiwa Daerah Surakarta. Available from: http://eprints.ums.ac.id/39438/ 18/NASKAH\%20PUBLIKASI.pdf

2. Badan Penelitian dan Pengembangan Kesehatan Republik Indonesia. Laporan Hasil Riset Kesehatan Dasar (Riskesdas) Nasional 2013; p. 110-7.

3. Badan Penelitian dan Pengembangan Kesehatan Republik Indonesia. Buletin Jendela Data dan Informasi Kesehatan. Jakarta: Kementrian Kesehatan Republik Indonesia, 2012; p. 8.

4. RM. Pentingnya kesehatan gigi dan mulut. [cited April 2016]. Available from: http://www.garutkab.go.id/download_fi les/article/Pentingnya\%20Kesehatan\%2 0Gigi\%20\&\%20Mulut.pdf

5. Herijulianti L, Indriani TS, Artini S. Pendidikan Kesehatan Gigi. Jakarta: EGC, 2001; p. 6-8.

6. Afni F. Dental Health Education/DHE Pendidikan/Penyuluhan Kesehatan/ Gigi/PKG. Available from: https://www.academia.edu/11729959/D ental_Health_Education_DHE_Pendidi kan_Penyuluhan_Kesehatan_Gigi_PK $\mathrm{G}$

7. Sadiman AS, Rahardjo, Haryono A, Harjito CAS. Media Pendidikan Pengertian, Pengembangan dan Pemanfaatannya. Jakarta: Rajawali Pers, 2014; p. 28-75.

8. Hurlock EB. Buku Psikologi Perkembangan Pendekatan Sepanjang Rentang
Kehidupan (5th ed). Jakarta: Erlangga, 2003.

9. Gambaran Oral Higiene Dan Perilaku Kebersihan Gigi Pada Murid Kelas V SD Di Daerah Rural Dan Urban di Kecamatan Medan Barat. [cited Jun 2011. Available from: http://repository.usu.ac.id/bitstream/123 456789/6991/1/10E00144.pdf

10. Sinor MZ. Comparison between conventional health promotion and use of cartoon animation in delivering oral health education. IJHSS. 2011;1(3):169-74.

11. Riyanti E, Saptarini R. Upaya peningkatan kesehatan gigi dan mulut melalui perubahan perilaku anak. [cited Oct 2010]. Available from: http://journal.unair.ac.id/filerPDF/DEN TJ-38-2-10.pdf.

12. Notoatmodjo S. Promosi Kesehatan dan Ilmu Perilaku. Jakarta: Rineka Cipta, 2007.

13.Purnama AP. Efektivitas penggunaan media video dan media leaflet terhadap perubahan pengetahuan dan sikap siswa tentang bahaya napza di SMP Negeri 3 Mojosongo Boyolali [Skripsi]. Surakarta: Fakultas Ilmu Kesehatan Universitas Muhammadiyah; 2013.

14. Nurhidayat $O$. Perbandingan media power point dengan flip chart dalam meningkatkan pengetahuan gigi dan mulut. Unnes Journal of Public. 2012. Available from: healthhttp:// journal.unnes.ac.id/sju/index.php/ujph

15.Azwar S. Sikap Manusia Teori dan Pengukurannya. Yogyakarta; Pustaka Pelajar, 2010. 